\title{
Reactions of Academic Librarians to Job Loss through Downsizing: An Exploratory Study
}

\section{Gloria J. Leckie and Becky Rogers}

\begin{abstract}
Because of budgetary constraints, many academic libraries are undergoing restructuring and downsizing of personnel. However, this has been occurring with very little discussion of how job loss affects the individual library worker. This exploratory study examines the impact of job loss on a sample of academic librarians from Ontario universities. The paper discusses the stages that individuals may pass through in coping with their job loss, and the stresses that they experience in dealing with their situation. The paper concludes with some recommendations about how sources of stress on individuals who are coping with job loss within the university setting could be reduced.
\end{abstract}

ver the past decade, academic libraries in both Canada and the United States have been undergoing a process of retrenchment, and academic library directors have been under pressure from university administrators to streamline their operations. ${ }^{1}$ This often has been accomplished through downsizing, involving budgetary cuts and concomitant organizational restructuring, particularly in the area of human resources.

Downsizing usually results in the identification of positions for elimination. Position elimination often is considered to involve only permanent positions, but this is only a partial view of overall human resource restructuring. The workforce can be reduced by flattening the managerial hierarchy, reducing the number of full- and part-time staff positions, and/or terminating ongoing contract positions (upon which many academic libraries have come to rely). Although the impact on the individuals affected is euphemistically described as forced displacement or involuntary redundancy, Carrie Leana and Daniel Feldman prefer the more general term job loss, defined as "any involuntary withdrawal from the work force, either by layoff or by firing." 2

In academic libraries, a growing number of staff, including librarians, have been affected by these various forms of job loss directly brought about by downsizing, yet the literature of academic librarianship is completely silent on this topic. Articles on academic librarians as staff members imply that once hired, trained, specialized, and developed, librarians never leave their institutions, or that they leave happily, willingly, and silently for greener pastures. However,

Gloria J. Leckie is an Assistant Professor in the Graduate School of Library and Information Science, University of Western Ontario, London, Ontario, Canada, N6G 1H1. Becky Rogers is Coordinator of Systems and Access Services at the Stratford Public Library, Stratford, Ontario, Canada. This research has been supported by a grant from the Social Sciences and Humanities Research Council of Canada. The investigators would also like to acknowledge the fine work of our research assistant, Susan Vermeulen, whose contribution was greatly appreciated. 
through reports of downsizing at universities across North America, we know this cannot be true.

For the most part, the human face of downsizing in academic libraries has been invisible. This study was devised to broaden our understanding of downsizing and job loss by exploring the effects on those who have gone through it, rather than on the institutions in which they have worked. While the human face of downsizing also includes managers who are put in the difficult position of having to implement these changes, this research concentrates on academic librarians who have experienced job loss themselves.

\section{JOB LOSS, STRESS, AND COPING}

This study falls within the scope of a large body of literature examining the psychosocial impacts of unemployment. Research on the unemployed first was undertaken seriously in the 1930s and was based on the classic study of the Austrian village of Marienthal by Marie Jahoda and colleagues. ${ }^{3}$ These early studies tended to focus on blue-collar workers, but some of the subsequent studies have also looked at white-collar workers and professionals. ${ }^{4}$ Although this research sometimes has provided contradictory findings, two of the most widespread conclusions are that (1) job loss is a major life trauma comparable to death, divorce, and serious illness, and is therefore inherently stressful, and (2) there are stages individuals pass through in reacting to, and coping with, the loss of their employment. ${ }^{5}$

For this study, the definition of stress suggested by Stephen Fineman is useful. ${ }^{6}$ In his view, stress is a psychological response state of negative affect, characterized by a persistent and high level of anxiety or tension. Stress is brought on by a stressor event that is perceived to be threatening to various aspects of the individual's personal well-being.

There are certain factors that can make unemployment stressful. Unemployment represents a loss, and the process of coping with loss can itself be stressful. But exactly what is lost through becom- ing unemployed? Jahoda has suggested that while loss of financial remuneration is often foremost on the mind of those who become unemployed, loss of other aspects of employment can be equally stressful. ${ }^{7}$ These aspects include sharing experiences with others outside the family, associating with larger goals beyond one's own, defining personal status and identity, structuring time, and providing regular activity.

For professionals, the loss of the identity gained through meaningful work can be particularly devastating. Harold Kaufman points out that studies of professionals and managers have shown that they view their work as being more central to their lives than do other types of workers. ${ }^{8}$ Furthermore, for professionals, there is a correlation between satisfaction with work and satisfaction with life. Thus it is not surprising that some research has suggested that higher-status workers are much more affected by job loss. ${ }^{9}$

Unemployment also represents a time of uncertainty and unpredictability. Individuals generally find a state of uncertainty to be stressful, although there are some facets of uncertainty that are more stressful than others. For instance, there is evidence that individuals who are relatively at risk financially experience more uncertainty and more stress than those who are financially secure. ${ }^{10} \mathrm{Re}$ search has also shown that the uncertainty, unpredictability, and the resultant stress of job loss can be minimized by factors such as the strength of the individual's social support network. ${ }^{11}$

People react to stress and stressful life events by coping, defined as a changing process directed toward managing both emotions and the problem that has caused the stress. ${ }^{12}$ Leana and Feldman put this a slightly different way, stating that people cope with stressful events by taking actions to establish new routines. In the case of job loss, coping is an active attempt to "gain reemployment or to regain some semblance of psychological well-being. ${ }^{\text {"13 }}$

\section{STAGES OF UNEMPLOYMENT}

Becoming unemployed is a very personal experience. ${ }^{14,15}$ People enter the 
TABLE 1

STAGES OF UNEMPLOYMENT*

\begin{tabular}{|c|c|c|}
\hline Stage & Title & Characteristic Reactions \\
\hline Stage one & Shock, relief, and relaxation & $\begin{array}{l}\text { Shock, initial reduction in stress } \\
\text { Relief, sometimes followed by relaxation } \\
\text { (take vacation time) } \\
\text { Anger, anxiety about future }\end{array}$ \\
\hline Stage two & Concerted effort & $\begin{array}{l}\text { Optimism, still feels in control } \\
\text { In need of social support } \\
\text { Vulnerable to stress, particularly over } \\
\text { finances }\end{array}$ \\
\hline Stage three & $\begin{array}{l}\text { Vacillation, self-doubt, and } \\
\text { anger }\end{array}$ & $\begin{array}{l}\text { High anxiety } \\
\text { Questions career choice, ability } \\
\text { Feels obsolete, out-of-date professionally } \\
\text { Extreme mood changes, irritability } \\
\text { High levels of frustration, anger }\end{array}$ \\
\hline Stage four & Resignation and withdrawal & $\begin{array}{l}\text { Loss of motivation and self-esteem } \\
\text { Feels loss of control over own life, } \\
\text { helplessness } \\
\text { Limited social relationships }\end{array}$ \\
\hline
\end{tabular}

* Adapted from Harold G. Kaufman, Professionals in Search of Work: Coping with the Stress of Job Loss and Underemployment (New York: Wiley, 1982).

situation with different belief systems and resources at their disposal, making it unlikely that two individuals will view their unemployment in the same way. Nevertheless, studies have demonstrated that at certain periods in the process of dealing with their unemployment, great numbers of people do have similar feelings. These feelings have been identified as components of the stages, or phases, in coming to terms with job loss. Recent proponents of the phasic approach, such as Kaufman, suggest that there are generally four stages, but emphasize that the duration and order of the stages can vary. ${ }^{16}$ The four stages are depicted in table 1 .

While many authors agree that the staged approach is valuable in understanding how job loss is experienced, there also has been criticism of this perspective. There are a multitude of factors that can affect how stages unfold for each individual, such as financial security, social support systems, previous job loss experiences, and personality factors, as well overall job prospects within the larger economy. Furthermore, much of the literature in this area assumes that "individuals are relatively passive agents who [merely] experience unemployment and its effects." ${ }^{17}$ In contrast, Leana and Feldman suggest that individuals should be viewed as active agents who behave in ways that affect the outcomes of job loss, and who make choices about how to cope with this event in their lives.

\section{OBJECTIVES}

The overall intent of the study is to develop a fuller understanding of the implications of downsizing in academic libraries by providing documentation on the impact of job loss on the lives of a sample of academic librarians. The primary objectives of the study are (1) to explore how academic librarians react to and cope with job loss, and (2) to examine the institutional and personal elements that produce or reduce stress for the individual in this situation. The research was never intended as a complete account of the impact of job loss within academic libraries, but rather as a means of initiating some discussion of the human side of downsizing and fostering a greater sense of the dislocations that all of us may be facing as our economy transforms. 


\section{METHOD AND SAMPLE}

The research was carried out in Ontario. Academic librarians who personally had experienced a position elimination (either permanent or ongoing contract) brought about by downsizing within the previous four years were sought as participants. The decision to include contract librarians was made in order to increase the visibility of this group of professionals, many of whom have worked on a quasi-permanent basis for their institutions and who are increasingly vulnerable to the elimination of this particular form of employment.

Volunteers were sought who would be willing to come forward and discuss the termination of their employment freely, without institutional involvement. Announcements were sent in the fall of 1992 and early 1993 to chief librarians and to department heads of nine university libraries located in close geographic proximity, asking them to post or circulate the notice of the study. An advertisement was also placed in a newsletter that serves the Ontario academic library community. Eleven librarians, who had worked at six different institutions, agreed to take part in the study. Because of the small number of participants, concerns about anonymity were heightened. Therefore, the description of the sample in the discussion that follows has been kept deliberately vague to avoid the possibility of linking any participant with a particular institution or locale.

Drawing on the methodology of accounts, the study used open-ended personal interviews that allowed each participant to recount in detail the circumstances leading up to the termination, the termination event itself, and the aftermath, focusing on the participant's thoughts, feelings, and actions at each stage of the process. ${ }^{18}$ The interviews typically lasted about two hours and were taped, then later transcribed and coded for content. ${ }^{19}$

The participants ranged in age from the late twenties to late fifties, with seven people over forty. The majority of participants were female, and held an
M.L.S. or equivalent. About half the sample had worked as professional librarians for twenty years or longer, and the most typical income range for the group was between $\$ 40,000$ to $\$ 50,000$ (Canadian). Eight participants had held permanent positions and three had held ongoing contract positions. While the majority worked within their university's library system, three participants worked within large departmental libraries not considered part of the formal library system. The average length of time spent in the eliminated position was between five and ten years.

\section{BECOMING UNEMPLOYED- INITIAL REACTIONS}

Upon being informed that their position was being eliminated, participants described being flooded with a variety of thoughts and feelings that progressed throughout the first twelve to twentyfour hours after the termination. The initial reactions of the participants differed according to their status within the institution. Those who had permanent positions had a slightly different reaction than those who were on contract, although there were also some similarities. Librarians who were older, had more senior positions, or had a greater length of service had different concerns than younger librarians or those with less seniority.

Since the severe financial constraints facing Ontario universities have been well publicized, none of those interviewed were totally unaware that job losses might occur within the institution. Despite this, most of the eight participants with permanent positions were quite surprised by the way in which events unfolded and that it was their own positions that were vulnerable. Five participants were caught completely offguard when the final decision to eliminate their positions was made known to them by their supervisors. For these individuals, the termination event truly did represent a shock. They had difficulty taking in what they were being told, as two participants indicate:

- When they gave me the news, it was a bit of a shock, but I didn't feel that bad 
at first. I didn't hit the floor. I didn't fall out of my chair [but] throughout the discussion, the implications of it, you know, hadn't hit me.... So I went out and back to my office and thought, well, I better get back to work, but I soon began to realize [and] to become progressively depressed, beginning to realize what the consequences would be.

- It was surreal. My memories of it are two distinct and separate images both running. You know, one being very serious about it, being concerned about my long-term career and the other kept saying, they've really done it! It was like a movie.

Other participants immediately felt angry and/or bitter that this was to be the outcome, but many noted that at the same time, they felt a tremendous sense of relief that the months of anxiety about what would happen were finally over.

Although the three contract librarians were not as shocked at the news that their positions were to be eliminated, nevertheless they did feel quite upset by the terminations. Contract librarians are relatively used to living with daily uncertainty about their long-term future within the institution, although this insecurity is often lessened by support from their colleagues who sometimes suggest that the contractual arrangement may lead to something more permanent if one can just "hang in." However well-intentioned this support is, unfortunately it has the effect of creating a false sense of hope that is dashed forever when the contract is finally eliminated. Although this is not quite the same as the shock of losing a permanent position, it still can feel devastating, particularly if the individual already has worked for the library for a number of years. One contract librarian recalls:

- I was just crushed, really. It was really difficult.... I'd been at the university for so many years .... and it was hard to think about not being there. But what I found really difficult that particular first night was knowing that I had to go back to work the next morning and ... act like everything was just fine.

While the element of surprise may have been different for permanent and contract librarians, individuals in both groups experienced the shock of the final decision in similar ways. To sort out their initial feelings in private, about half of the sample took time off, ranging from an afternoon to several days. During that period, these participants described feeling increasingly anxious and/or depressed:

- [I was thinking] What on earth is going to happen? Because that is the kind of thing that starts to come on, you can't comprehend, sort of, not having a job. ... And most of it was spent rehashing the days and trying to accept the reality that this had really happened, and trying not to panic.

\section{IMPACT OF AGE AND SENIORITY}

Along with the status of the eliminated position, the age and seniority of the individual also appear to have an impact on the initial reaction to job loss, as other research also has suggested. ${ }^{20}$ Since over half of the sample had almost twenty years of experience or longer, worries about age and career interruption surfaced almost immediately for these participants.

Participants in their late forties and early fifties immediately felt great apprehension at what would happen to them as older workers being cut adrift in an economy where there is a trend toward a greater reliance on part-time and contract work. Some worried that they might not be hired by younger managers, while others were concerned that given the state of the economy, they might conceivably never be able to work full time again:

- When I realized this was going to happen, I mean, there was no good trying to kid myself that I'm going to get a full-time job, maybe I am, but the way things look at the moment, I think it's very unlikely. 'Cause (a) so few jobs and (b) being much older.

For other older librarians, however, foremost on their minds was the impact that the termination would have on their careers. Some immediately worried that their capabilities would be called into 
question, and wondered how they should handle this in future job interviews. There were also concerns about the implications of perhaps working at a lower level within the same library system and the loss of status this would entail. Finally, some older librarians were worried about their skill level in having to compete with younger librarians who had been exposed to new technologies:

- I really did not see myself as having any prospects. ... I'm very experienced but, I'm thinking of pre-computer days, I felt that I was obsolescent in a very real sense in terms of trying to move somewhere else. . . . I was quite conscious of being part of a generation that has passed, so to speak.

For younger or less experienced librarians, the termination was not necessarily less stressful, but they did have a slightly different outlook. Four librarians were either under forty years of age or had under five years' experience as professionals when their positions were eliminated. For this group, there was noticeably less apprehension about the long-term impact of the termination, and slightly more optimism about options. However, there was still concern about the economy, the possibility of having to settle for part-time work, and the stigma of being unemployed:

- There is the perception that if you're not working, it is harder to get hired, but if you're working in a job, then it is easier to be hired ... [ [It's] I don't know, some kind of stigma. ... You always look better when they are stealing you away from someone else than if you are out there and you're not working.

\section{FINANCIAL STATUS}

Research has shown that the fiscal stress of unemployment has been considerably lessened since the inception of unemployment insurance during the 1940 s. $^{21}$ In the short run, financial concerns may no longer be as prominent for the unemployed, as Penny Swinburne found. ${ }^{22}$ To a certain extent, this was also true in the present study, but may have been partly due to the age range of this particular group, most of whom had been working for over fifteen years and had significant personal resources at their disposal.

For many participants, however, the short-term availability of unemployment insurance did nothing to alleviate the worry over what would happen when this support was finished. This theme permeated their efforts to cope with job loss, adding to the stress they experienced. Some had made financial commitments that they worried they could not sustain in the long run, while others were anxious that they might never return to a regular income and thus would be unable to replace major needed items:

- I need a new car at the moment. My car is ten years old and going around the clock for the third time.... When it comes down to the bottom line, if you can't buy something, or you can't pay for something [then you really worry].

Financial uncertainties were compounded by the impact the job loss would have on retirement planning. Most participants were either not quite close enough to retirement age, or felt they could not afford, or did not want, to retire. The loss of their position and all that they had built up toward retirement was a real blow. Concern over this issue is certainly not misplaced, since there is ample evidence that Canadian workers with higher incomes are better prepared financially to sustain themselves during their retirement years. ${ }^{23}$ One participant, who lost a full-time position and was able to secure only a short-term contract, comments:

- My salary has gone backwards $\$ 10,000.00$... I I would dearly love to retire by the time that I am sixty. That gives me ten years and ... I'm going backwards in pay every year towards my retirement... So you start to think of all these things and wonder, should you get out? What am I doing fiddling around in this low-level contract job? But what alternative is there right now? Very few of the older participants felt that they could seriously consider retire- 
ment as a financial option. However, participant \#8 was financially able to opt for early retirement and felt a sense of empowerment (and a reduction of stress) at being able to control the situation:

- I won't say I didn't go through periods of anguish on this but really, once I'd made the decision [it was better] ... . because it wasn't done to me, I did it. That is the real difference, I think because I started [thinking about it ] as soon as I got the inklings ... It gives you a whole different perspective... I think you get a different feeling about it and different responses from someone who had it done to them instead of doing it.

\section{REACTIONS OF COLLEAGUES}

Besides the individual directly concerned, the shock of the termination also affects coworkers, many of whom experience the same sense of disbelief as the terminated employee. One librarian described this by saying, "I think shocked and stunned fit most of the people." As well, there is also a growing body of literature that addresses the issue of layoff survivor effect among the coworkers of terminated employees. ${ }^{24}$ Survivors may experience a range of reactions, including anxiety, guilt, anger, and relief. For many librarians in the study, dealing with the unpredictable reactions of colleagues added yet another element of uncertainty.

Participants generally described two types of reactions by colleagues-support and avoidance. The support and sympathy of colleagues was generally viewed as helpful, particularly in reassuring the participants that the termination was not their fault. However, coworkers reacting out of shock sometimes became unusually demonstrative in their support, with the result that participants who experienced this felt extremely uncomfortable and awkward. As one participant remarked, "The people that came up to you and put their arms around you and cried were the ones who were the hardest to take."

The other type of colleague reaction mentioned was avoidance, which can arise becausesurvivors feelguilty about what has happened to their coworkers, or are anxious about the vulnerability of their own positions. Viewed from the perspective of theterminatedemployee, avoidance had the effect of making them feel isolated and targeted. Two participants who experienced this comment:

- I could tell there were averted glances, people not really wanting to look at you when they pass you in the hall because they knew and didn't know what to say to you. People who felt guilty because they hadn't maybe stood up for us more. Then people who were absolutely stunned, who thought, Oh God, I might be next. . . . It sort of felt very strange.

- Some people were feeling a little badly because I suspect that on all the consultations that went on, they might have indicated that my position could be eliminated, and it was. There might have been a little bit of guilt afterwards.

Another stressful element of dealing with colleagues resulted from returning to work to finish out the period of termination notice or terms of the contract. The librarians in this study were generally determined to carry on with "business as usual." Although they saw this as part of their dignity as a professional, having to "pretend everything was fine" was a stress-filled deception in itself. Furthermore, participants who were managers had the added stress of having to deal with departmental turmoil over the announced downsizing, which often affected other staff members as well:

- The very next day there was a meeting to tell the whole staff. And then I immediately felt I had to deal with them.... I called the key people and tried to say positive things about how I thought this was all going to work.... So I was trying to reassure those people, trying not to focus on my problem.

\section{THE SEARCH FOR EMPLOYMENT AND ALTERNATIVES}

The librarians who took part in this study very quickly began the process of searching for new employment or other options (such as upgrading). The search 
process typically began within a day or so of having been told of the termination, often while they were still in a state of shock. Thus, for the majority of the sample, stages 1 and 2 of the job loss event occurred in a parallel, rather than a chronological, fashion.

The first goal of most participants was to concentrate their efforts on staying within the university system, enabling them to keep their benefits and pensions intact. This activity inevitably brought them again into contact with the university or library personnel department to ask for advice in clarifying various aspects of their situation. Seven of the eight participants who interacted either with the university or library personnel department had slightly to extremely negative comments about this experience. Their comments centered around two issues-placement procedures for redundant employees, and a perceived lack of preparation and sensitivity in handling position elimination.

Several librarians experienced a great deal of anguish at having to deal with their university's redundancy policy. The policies encountered by participants typically stated that redundant employees would be given preferred treatment and that efforts would be made to help them find another position within the university. However, the policy and the practice frequently did not mesh. These librarians experienced being ignored by the very personnel departments that were supposedly assisting them. Participants described not being informed of campus positions for which they would have been qualified, and/or not being considered for even the most junior vacancies (including library positions), despite having met the prerequisites.

Although there are too few cases to generalize, these accounts seem to indicate that there is resistance within some universities to placing redundant employees. For librarians, this is compounded by the fact that their skills and abilities appear to be undervalued and misunderstood by those involved in general university placement. For instance, participant \#3 applied for a lower- level, nonlibrary position for which she met all the requirements. The position involved liaison with students, dispensing relevant information, and working with a large database, all of which she had done for years as a departmental librarian. She was shocked and dismayed to learn that the interview committee did not consider her to be even remotely qualified for the position.

Participants also perceived that campus personnel departments were surprisingly unprepared to handle redundant employees, and were insensitive to their needs. Several participants commented that the process of finding the correct information was made very difficult, as their requests were often shuffled from person to person, adding to the humiliation and stress they experienced:

- I thought what the university should have done was gather together everything about that employee's case and sort of pull it all together and designate one person to deal with it.... In fact, I had to explain the situation to any number of people in the organization. I kept getting answering machines, I kept getting people who had no idea who I was or what had happened, and I got really tired of explaining it. ... [ [ was treated] as a routine person leaving, and it wasn't a routine case, but there was no sensitivity to the position that I was in.

For contract librarians, invisibility and lack of permanent status greatly affected their treatment within the system. While all three contract participants realized they were not eligible for the on-campus support mechanisms available to regular staff, this struck them as being unfair, and left them feeling excluded from campus information and employment opportunities:

- I was applying for whatever came up in the university system, but it seemed there was always someone in the wings waiting, and of course, I was considered an outside applicant even though I had worked for them for years.... Sometimes I would apply for an internal job and they wouldn't even acknowledge my application. ... That 
was hurtful, really, because you work for them and then you are just a nobody.

While efforts to stay on campus were being made, most participants were also investigating off-campus employment and gathering information on other options. This activity was constrained by the fact that all but one of the participants interviewed had significant ties to their community, and wanted to stay in their locality. Nevertheless, within these constraints, participants moved forward in their search for alternatives. This meant plugging into established networks of colleagues in other libraries to "shake the bushes" for upcoming vacancies, primarily within the local region, although several participants made inquiries about positions that would have required relocation. It also meant following up on job ads and going for information interviews, both of which participants did within days of their terminations. Other options investigated included going back to school, upgrading computer skills through a government program, and starting a small business. A few librarians also sought information on the procedures for collecting unemployment insurance. Generally, the efforts made by this group are consistent with findings from other research-searching for employment, seeking retraining, seeking to relocate, and investigating sources of financial assistance are among the most common strategies in coping with job loss. ${ }^{25}$

\section{SELF-DOUBT AND ANGER}

Kaufman has suggested that stage 3 begins a considerable length of time (possibly months) after the termination event. This partially did seem to be borne out by the librarians in this study, some of whom indicated that feelings of self-doubt and anger began to intensify the longer their reduced circumstances persisted, and in some cases even when they had become successfully reemployed. However, it should also be pointed out that some participants experienced self-doubt at the very beginning of the process of coping with their job loss, particularly if issues such as age were of concern.

Self-doubt frequently was expressed by the participants in terms of their selfesteem or self-worth, which was viewed as being low or reduced as time went on. After a certain period, self-doubt even began to color their perception of the termination event. This was one of the most striking aspects of stage 3 reactions, as almost all of the participants remarked that they began to wonder if the termination actually was a result of their own inadequacies, and was not just a result of downsizing. Three participants speculate:

- You wonder if your reputation precedes you and it's because maybe people think you were difficult to get along with .... or the fact that you were redundant in the first place is because you were a crummy worker or something. . . . My feelings of self-worth have really gone up and down. Like I keep thinking when you have those disappointments [in your job search], you think, What is it? What is wrong with me? Why can't I get a job? Why don't they want me?

- On the one hand, I felt unappreciated, and on the other hand, I mean, it does attack your confidence and your selfesteem, and whether you really have been doing as good a job as you'd thought you'd been doing.... There is this nagging doubt in the back of your mind, maybe they singled you out because you were incompetent rather than the reasons that were given.

- I was already going into the phase of doubting my own, not necessarily competence, but the track record I thought I had. I began to doubt-that it had been all in my mind and that it wasn't a real track record.

Feelings of self-doubt were also frequently accompanied by anger, bitterness, and/or frustration over various aspects of the downsizing, not only at what had happened to the individual but at the perceived long-term effects of downsizing on the library and on the profession. Librarians who had worked for a large part of their career within a 
particular library or library system felt angry at what they regarded as the dismantling or reduction of the library they had worked so hard to build. This was also accompanied by frustration over what many librarians considered to be a dangerous trend toward deprofessionalization, particularly in the cataloging and reference areas:

- I think what management wants is a layer of really high level management, and then a bunch of lower level clericals. I don't think they want any of the technical people [librarians] in between. The skilled people... [The catalogue] is our primary reference tool. And plus, everybody all over the world has access to these catalogues now. We have to make that tool as self-explanatory, and as reliable and as revealing as possible. We spend all this money getting it this way, why throw it away now?

- [The library] lost a [full-time] position and then they cut part-time staff, and the budget, and acquisitions. So it was a whole bunch of things all at once.... I couldn't see how they expected the collection to stay at the world status that it had, and be their showpiece that they always bragged about it being. It's eventually going to come back in their face if they don't staff the library properly.

\section{LATER REACTIONS: FINDING THE GOOD IN THE BAD?}

The final stage of coping with job loss is resignation and withdrawal, terms which in themselves assume a certain passivity. However, these descriptors really do not fit the later reactions to job loss as experienced by this sample of librarians.

What was the outcome of position elimination for the participants? At the time of their interviews, three librarians were unemployed, either through inability to find another position or through choice. Five others had eventually moved into other professional positions on campus, four as librarians and one within the university's administrative branch. Three ultimately had been successful in obtaining off-campus library positions.
Despite the fact that most of the sample had secured other positions, the impact of the job loss experience was still very much with them. Participants described bouts of severe depression, feelings of anger and bitterness, and a recurring uncertainty about their selfworth and capabilities. Even after moving into a new position, some librarians felt that their confidence had been seriously undermined:

- I discovered after I'd been there about a month just how much the experience had affected me because I was... very tentative about all the decisions and things which I would have done with ease before. I would now question myself whether I should do them or whether I had the right to do them.

- You get down on yourself and you think how come I'm not working and how must other people see me.... So now I am ... working reference, which is something I really like to do. That is such a boost, too, because . . . they didn't have time to give me very much training [but] I handled it really well. So all this has built up my confidence [again].

Were there any positive aspects to job loss as experienced by these librarians? Despite all the stress that they had been through, some admitted that there were. Several went on to procure positions that were either more challenging or more suited to their career goals and lifestyle. Another took a temporary part-time position which enabled her to add some valuable experience to her resumé. Even for those who had not found employment, there was still room for optimism, as indicated by this participant:

- In a situation like this, if you're not completely destroyed by the whole thing, there's tremendous opportunities. You get a chance to see different things. I find this very stimulating. You know, it's not all doom and gloom in my case. On the other hand, I could see if you were a single mother and you didn't have a job, you'd be suicidal. I just happen to be very lucky, in that I don't have dependents and things that would change the whole picture. 


\section{DISCUSSION}

There is evidence from the accounts of those interviewed that the staged approach to coping with job loss is still relevant in describing what happens to individuals whose employment is terminated. The participants recounted many of the same thoughts and/or reactions as have been reported in the literature on the stages of coping with job loss. At the same time, this study also supports Norman Feather's assertion that there is a great deal of individual variation in this regard. ${ }^{26}$ Some of the participants appeared to cycle through the stages relatively quickly, while others did not. It is also clear that most participants did not experience the stages in an orderly, chronological fashion. Despite the variability, it does seem that a general awareness of the staged approach to coping with job loss is useful in developing our understanding of what terminated employees may be experiencing in the hours, days, and months following a job loss event.

Although accounting for the variability of individual reactions is beyond the scope of the study, some factors did emerge as being more important than others. Age is one such factor-the librarians approaching age fifty or older appeared to experience greater stress than younger librarians. Interestingly, this is contrary to some research findings that suggest job loss is the most stressful for those in their thirties, and that for those fifty or older, the stress of job loss is much less. ${ }^{27}$

Other factors which seemed to play a part in the reactions of individuals to job loss were the degree of surprise experienced, status of the eliminated position (contract or permanent, management or staff), reactions of colleagues, length of service in the university, and length of the participant's library career. While monetary issues are a central theme in much of the research on unemployment, the role of financial status in this study is much less clear. Although financial concerns were mentioned by all participants, the impact that the job loss would have on the individual's career seemed to be equally worrisome for most. While this may have been partly because of the makeup of this particular sample, it may also suggest that, as professionals, these librarians were strongly identified with their careers.

The experiences of this sample reinforce the fact that job loss is extremely stressful and that dealing with ongoing uncertainty (of issues related to age, career, finances, self-worth, etc.) maintains or even escalates this stress. However, most of the librarians interviewed acted relatively quickly to explore options, underscoring the perspective that terminated employees are not passive victims but are actively coping by making attempts to give meaning to their personal situation and to exert some control over possible outcomes.

\section{CONCLUSIONS}

As academic and research libraries struggle to fulfil their mandate with reduced fiscal resources, it is inevitable that various forms of downsizing will continue, and that some library workers will be directly affected through position elimination. Given such trends, what can be learned from this exploratory research that would be helpful to those in academic libraries who are involved in this process?

First, it appears that a basic understanding of how terminated employees may react to the elimination of their positions is often lacking, both on the part of managers and colleagues. A plan of action for dealing with position elimination should be in place so that it is not left to the terminated employees to (1) explain the termination, or (2) reassure their colleagues, at the very time when the employee is experiencing shock and the onset of anxiety.

The reactions of colleagues are also a complex aspect of job loss that should not be overlooked. The participants in this study found genuine colleague support to be reassuring and helpful, yet coworkers may also be experiencing anxiety and may be uncertain how to respond. One possible solution to this is to provide guidance in this area as part of the professional development of library managers, so that they can act as 
role models for other staff should such a situation arise.

Second, the experiences of the librarians in this study point to a need for greater coordination between university units (such as the library or academic departments) and the university's personnel department to ensure that redundant and/or terminated employees are not left to fend for themselves at a time when they are extremely vulnerable. The most obvious suggestion here is that ideally there should be a personnel officer assigned to assist the employees in resolving all of the questions they have about their situation. Furthermore, it is not necessarily true that personnel officers always know what to do when interacting with redundant employees. ${ }^{28}$ At the very least, more training would seem to be warranted.

The accounts of this sample also suggest that the corporate culture of some universities is such that redundancy is not taken seriously, despite the fact that this is becoming (or threatens to become) increasingly widespread. Policies with respect to redundant employees were often ambiguous, and/or were not implemented as written, leaving many in this study feeling that they had been treated unfairly. Contract and departmental librarians in particular perceived that they were not considered for general library positions because they already were considered marginal and expendable. It seems that in many cases, clarity and honesty in dealing with redundant employees are missing ingredients. Academic libraries could exhibit some leadership in this regard by ensuring that they are not merely giving lip service to the university's overall commitment to redundant employees.

Third, the research suggests that greater access to information on the implications of position elimination and job loss is desirable. Participants perceived a conflict of interest between their right to be informed of all possible options, and the obligation of managers and personnel officers to represent the interests of the university. As one librarian was told by an outside contact, "Just remember who they are working for, and it is not you." Participants described feeling that they could not trust what they were being told, or that they were not made aware of all the alternatives. This would suggest that a third-party consultant should be made available to redundant employees to assist them in their information gathering and decision making.

Ultimately, terminated employees want to be treated with respect and to leave their position in a manner that enables them to maintain their dignity, as Leana and Feldman also emphasize. ${ }^{29}$ If left to chance, this may not happen, leaving the individual to cope with feelings of bitterness and resentment, and the institution to deal with the added factor of ill will. One participant summed this up quite aptly:

- The one thing they won't be able to say is that I didn't leave with dignity. I did not want to become the object of pity.... Organizations really need to work with the employees who are left behind in terms of how to treat the people who get dumped. Dealing with them as people is really important.

\section{REFERENCES AND NOTES}

1. Ethel Auster, Retrenchment in Canadian Academic Libraries (Ottawa: Canadian Library Association, 1992); L. Christinger Tomer, "The Effects of the Recession on Academic and Public Libraries," Bowker Annual Library and Book Trade Almanac (New York : Bowker, 1992), 74-84; and Murray S. Martin, "Stagnant Budgets: Their Effects on Academic Libraries," Bottom Line 3 (1989): 10-16.

2. Carrie Leana and Daniel Feldman, "Individual Responses to Job Loss: Perceptions, Reactions and Coping Behaviors," Journal of Management 14 (Sept. 1988): 375-89.

3. Marie Jahoda, P. F. Lazarsfeld, and H. Zeisel, Marienthal: The Sociography of an Unemployed Community (New York: Aldine-Atherton, 1933). 
4. See review in Norman T. Feather, The Psychological Impact of Unemployment (New York: Springer Pub., 1990).

5. Marie Jahoda, "The Impact of Unemployment in the 1930s and 1970s," Bulletin of the British Psychological Society 32 (Aug. 1979):309-14, and Harold G. Kaufman, Professionals in Search of Work: Coping with the Stress of Job Loss and Underemployment, (New York: Wiley, 1982).

6. Stephen Fineman, "A Psychosocial Model of Stress and Its Application to Managerial Unemployment," Human Relations 32, (Apr. 1979): 323-45.

7. Jahoda, "Impact of Unemployment," 312-13.

8. Kaufman, Professionals in Search, 22.

9. Ibid., 23.

10. R. J. Estes and H. L. Wilensky, "Life Cycle Squeeze and the Morale Curve," Social Problems 25 (Feb. 1978): 277-92.

11. Feather, Psychological Impact, 61, and Kaufman, Professionals in Search, 35.

12. R. S. Lazarus and S. Folkman, Stress, Appraisal and Coping (New York: Springer Pub., 1984).

13. Carrie Leana and Daniel Feldman, Coping with Job Loss (New York: Lexington Bks., 1992), 80.

14. David Jacobson, "Models of Stress and Meanings of Unemployment: Reactions to Job Loss among Technical Professionals," Social Science and Medicine 24 (June 1987): 13-21.

15. Penny Swinburne, "The Psychological Impact of Unemployment on Managers and Professional Staff," Journal of Occupational Psychology 54 (Mar. 1981): 47-64.

16. Kaufman, Professionals in Search.

17. Carrie Leana and Daniel Feldman, "Individual Responses to Job Loss: Empirical Findings from Two Field Studies," Human Relations 43 (Nov. 1990): 1156.

18. Jennifer Brown and Jonathan Sime, "A Methodology for Accounts," in Social Method and Social Life, ed. M. Brenner (London: Academic Pr., 1981), 159-71.

19. Barbara Mostyn, "The Content Analysis of Qualitative Research Data: A Dynamic Approach," in The Research Interview: Uses and Approaches, ed. M. Brenner, J. Brown, and D. Canter (London: Academic Pr., 1985), 115-45.

20. Leana and Feldman, "Individual Responses."

21. Kaufman, Professionals in Search, 95-96.

22. Swinburne, "Psychological Impact."

23. Susan Crompton, "Facing Retirement," Perspectives on Labour and Income 5 (Spring 1993): 31-38.

24. David Noer, "Layoff Survivor Sickness: A New Challenge for Supervisors," Supervisory Management 35 (Mar. 1990): 3. Also Joel Brockner, "The Impact of Layoffs on the Survivors," Supervisory Management 31 (Feb. 1986): 2-7.

25. Leana and Feldman, Coping with Job Loss.

26. Feather, Psychological Impact.

27. Kaufman, Professionals in Search, 62.

28. Shirley Middlebook and Edward Clarke, "Emotional Trauma of Job Loss: How to Interact and Cope with Laid-off Employees in Distress," Employee Assistance Quarterly 7 (1991): 63-65.

29. Leana and Feldman, Coping with Job Loss, 137. 